\title{
“QUEM JÁ RIU DE UM FILME DE TERROR?”: DISTINÇÃO E SOCIABILIDADE NO CONSUMO DE CULTURA TRASH ${ }^{1}$
}

\author{
"ANYONE WHO HAS LAUGHED IN A HORROR MOVIE?": DISTINCTION \\ AND SOCIABILITY IN THE CONSUMPTION OF TRASH CULTURE \\ "CUALQUIERA QUE HAYA REÍDO EN UNA PELÍCULA DE TERROR?": \\ DISTINCIÓN Y SOCIABILIDAD EN EL CONSUMO DE LA CULTURA TRASH
}

Mayka Castellano

UFRJ

maykacastellano@gmail.com

\begin{abstract}
Resumo
Neste artigo, abordo a questão do humor presente na fruição de produções alinhadas ao gênero terror realizada pelos jovens integrantes da subcultura do trash. Amparada em entrevistas em profundidade e em uma etnografia virtual, analiso os debates desenvolvidos, no interior dessa comunidade, sobre a pertinência ou não do riso e suas motivações. Articulo, por fim, o debate sobre o humor em um quadro mais geral que explica o consumo do chamado "lixo cultural" através da lógica da distinção.
\end{abstract}

Palavras-chave: cultura trash; subcultura jovem; riso ; terror.

\begin{abstract}
In this paper I approach the issue of humor in the enjoyment of productions aligned to the horror genre performed by young members of the trash subculture. Supported by in-depth interviews and a virtual ethnography, I analyze the debates about the relevance of the laughter and their motivations developed within that community. Finally, I articulate the discussions about the humor in a more general framework that explains the use of the "cultural garbage" in the logic of distinction.
\end{abstract}

Keywords: trash culture, youth subculture, laughter, terror.

\section{Resumen}

En este artículo se aborda la cuestión del humor presente en el consumo de producciones alineadas al género de terror realizado por jóvenes miembros de la subcultura "trash" . Con el apoyo de las entrevistas en profundidad y una etnografía virtual, se analizan los debates desarrollados en esta comunidad sobre la conveniencia o no de la risa y sus motivaciones. Finalmente, desarrollo el debate sobre el humor en un cuadro más general que explica el uso de la llamada "cultura basura" a través de la lógica de la distinción.

Palabras clave: cultura trash, subcultura juvenil, risa, terror.

\footnotetext{
${ }^{1}$ Uma versão deste trabalho foi apresentada no XXXIII Intercom - Congresso Brasileiro de Ciências da Comunicação, em 2010.
} 
Uma das subculturas mais atuantes na internet hoje é a dos fãs de cultura trash. Em sites, blogs, fóruns de discussão e comunidades de redes sociais, jovens (principalmente homens, de 14 a 35 anos, de classe média, moradores de grandes centros urbanos ${ }^{2}$ ) se reúnem para debater sobre o que há de pior em termos de audiovisual. Um produto pode ser considerado trash devido ao seu amadorismo ou ao fato de ser considerado "horrível", o que passa por um julgamento estético. Normalmente, tornam-se engraçados através de uma peculiaridade, amiúde associada à má qualidade técnica ou à discrepância das normas do "bom gosto".

Nesse sentido, trabalho com a ideia de cultura trash associada ao conceito de paracinema desenvolvido por Sconce (1995). Para o autor, paracinema não é apenas um grupo distinto de filmes, mas, principalmente, uma forma específica de leitura de determinadas produções audiovisuais, outra sensibilidade estética e subcultural, que valoriza todo o tipo de "lixo" e, dessa forma, pode reunir uma variedade espetacular de subgêneros. O autor cita como possíveis exemplos o terror e a ficção científica (categorias clássicas do trash), além de produções como uma campanha governamental de higiene, um vídeo caseiro sobre as férias em família, um pornô sadomasoquista, um strip-tease com grávidas, documentários sobre necrofilia ou zoofilia, um filme japonês de monstros, musicais

\footnotetext{
${ }^{2}$ Para a realização deste artigo, e de minha pesquisa para a dissertação como um todo, realizei a observação participante em quatro sessões do cineclube Phobus (realizadas no Sesc Tijuca, no Rio de Janeiro) e em préestreias de dois filmes - "Encarnação do Demônio" (2008), de José Mojica, e "Planeta Terror" (2007), de Robert Rodriguez, ambas no cinema Arteplex, localizado em Botafogo, bairro da Zona Sul do Rio de Janeiro. Além disso, empreendi a prática metodológica da entrevista em profundidade com alguns jovens fãs de cultura trash. A forma de abordagem escolhida foi a análise dos perfis de membros de comunidades específicas do site de relacionamentos Orkut: "Trash, Gore e Terror em Geral" e "Filmes Trash Caseiros", formadas, respectivamente, por admiradores de filmes de terror e fãs de trash que produzem seus próprios filmes. Ao me associar a essas comunidades, pude ter acesso a todo o conteúdo produzido (como fóruns de discussão, agendamento de eventos e enquetes formuladas pelos integrantes). Acho interessante, no entanto, ressaltar que minha participação restringiu-se à observação das conversas desenvolvidas nos tópicos e do restante do conteúdo. O processo de observação dos perfis levou-me não somente à escolha dos 23 fãs com quem entrei em contato por telefone, MSN ou Skype, mas revelou uma eficiente ferramenta na busca de informações e pistas sobre quem eram aquelas pessoas e como se dava a relação mantida entre elas através do site. Dos 23 fãs entrevistados, apenas quatro eram do sexo feminino, número que correspondia à proporção de mulheres nas comunidades analisadas. A amostragem com que tive contato e a análise do perfil de outros membros através dos dados disponibilizados no Orkut permitiram a constatação de algumas características marcantes neste conjunto de fãs. Além de predominantemente masculino, o público de trash é, também, notavelmente jovem. A faixa etária dos entrevistados variou entre 14 e 31 anos e mesmo os mais velhos apresentam um estilo de vida normalmente associado à juventude: estudam, não trabalham em período integral, não são casados e moram com os pais. A forma de abordagem dos entrevistados (uso dos mecanismos da Internet) levou a um grupo pertencente exclusivamente à classe média. No caso da comunidade de fãs de trash, a associação entre capital cultural, subcultural e econômico é bastante clara, dada a necessidade de acesso a computadores conectados à rede e dotados de determinadas especificações que tornam possível o download e a apreciação dos filmes digitais.
} 
adolescentes sobre festas na praia, cinebiografias de celebridades, como Elvis, um vídeo de treinamento para funcionários do Mc Donald's etc.

A chave para compreendermos esse tipo de fruição está na constatação de que, ao consumirem tais produtos, esses indivíduos realizam um processo de reciclagem cultural, que consiste basicamente na transformação de produtos da mídia identificados com o mais baixo estrato da cultura de massa em marcas de autenticidade e de distinção social. Não se trata simplesmente do consumo de produtos de baixa qualidade artística, e sim do consumo associado à consciência da má qualidade, sendo observada nessa atitude algo de meritório, a partir do que construirão seus estilos de vida e signos de diferenciação.

Se muitos assuntos movimentam essa comunidade de fãs, um, em particular, atiça os ânimos desses jovens consumidores e produtores de "lixo cultural": o humor involuntário causado por muitas dessas produções. É “certo" rir de um filme de terror? Existe alguma cartilha de decodificação para a cultura trash? O que torna uma morte violenta ou uma cena de sofrimento em um filme algo engraçado? A partir de questões como a citada no título, que foi tema de discussão em uma comunidade dedicada ao trash no Orkut, discuto o ideal de autenticidade e diferenciação envolvido no consumo deste tipo de artefato. Para isso, começo fazendo um breve levantamento teórico sobre a questão do riso e suas possíveis motivações, buscando pontos de interseção entre as noções de humor e de busca por distinção e superioridade.

\section{Notas sobre o riso}

Na Antiguidade, encontram-se muitas das premissas que são usadas até hoje na explicação do fenômeno do riso. Aristóteles faz menção às implicações do riso quando discute o comportamento da juventude, no livro II da Retórica, em que defende que uma das características dos jovens é serem "zombeteiros", "amigos da alegria”, e, portanto, "adoram zombar dos outros" (apud Skinner, 2002: 15). Para ele, "a zombaria é um insulto gracioso" e o insulto "a degradação do outro por diversão". Segundo Skinner, "a sugestão básica é que a alegria induzida pela zombaria é sempre uma expressão de desprezo, de escárnio" (2002: 16).

Nesse ponto, a teoria de Aristóteles se aproxima de um assunto muito pertinente para este artigo: o riso na fruição do trash funciona como forma de legitimação e demonstração de 
capital subcultural ${ }^{3}$ e superioridade. Ou seja, quando mais importante não é do quê se ri, mas como se ri, na companhia de quem, e para quais propósitos. A análise prática desse tipo de riso se dá, então, na verificação da sociabilidade mantida em torno desses produtos. Ao mesmo tempo, se Aristóteles apenas toca nesse assunto, para outros estudiosos é justamente através da sensação de superioridade que o estudo do riso vai se justificar.

Cair de repente nos dispõe a chorar. Ver os outros caírem nos dispõe a rir (THOMAS HOBBES apud SKINNER, 2002: 56)

Os estudos que analisam o riso sob a perspectiva da superioridade costumam citar Thomas Hobbes como o principal representante dessa linha teórica. Consciente de que o esse tipo de riso encontra suas origens nos escritos da Antiguidade, ao desenvolver sua teoria sobre o fenômeno, é principalmente em Aristóteles que Hobbes vai se basear. Ele estuda o riso a partir da discussão sobre as paixões. Segundo o autor, a paixão que o suscita é o orgulho que sentimos ao percebermos nossa capacidade ou superioridade: "quando experimentamos a súbita intuição de nossa diferença e superioridade, nós mesmos fervilhamos de alegria" (SKINNER, 2002: 52),

Devemos entender essa concepção tendo em vista o quadro de seu sistema filosófico, ou seja, compreender que, assim como todas as paixões, o riso está a serviço das relações de poder entre os homens, de sua natureza política (ALBERTI, 1999).

As principais críticas à teoria do riso da superioridade, de Hobbes, se fixaram em duas premissas bastante simples: nem todo riso é a constatação da nossa superioridade, nem toda constatação de superioridade leva ao riso. O fato é que o próprio autor tem consciência desses limites, e, inclusive, o ponto de vista sobre esse tipo de motivação para o riso é duramente repreendida por ele em Leviatã, quando acusa de pusilanimidade aquele que ri dos defeitos alheios, já que os espíritos elevados devem comparar-se apenas aos mais hábeis.

A associação entre riso e superioridade também foi a tônica da análise de Baudelaire. Em De l'essence du rire et généralement du comique dans les arts plastiques (1855), o autor expressa a ideia de que o riso comporta uma dimensão de orgulho por não sermos nós os protagonistas de certos disparates. Um exemplo que ele dá é a clássica situação de quando

\footnotetext{
3 "Capital subcultural" é uma adaptação de Thornton (1995) para o conceito "capital cultural" de Bourdieu (2007). Refere-se à competência e ao conhecimento acumulados no uso dos códigos de uma subcultura, familiaridade com os estilos e gêneros valorizados internamente no grupo e que conferem prestígio a quem sabe manejá-los (BOURDIEU, 1997; THORNTON, 1995; FREIRE FILHO, 2007).
} 
alguém cai: rimos porque desenvolvemos um sentimento de superioridade, que pode não ser consciente, mas que aparece diante da constatação de que, diferentemente daquele sujeito, nós continuamos caminhando tranquilamente pela rua. Assim, nosso riso seria, antes de tudo, “dirigido contra a fraqueza e o infortúnio dos outros" (BAUDELAIRE apud HAUGEN, 1988: $13)$.

Apesar de não citar diretamente Hobbes dentre as suas referências, Baudelaire se aproxima do inglês na hora de fazer um julgamento moral sobre o riso, classificando o ato de "um fenômeno deplorável", pois se trataria da "fraqueza regozijando-se às custas da fraqueza", pela mesmo lógica hobbesiana de que os bons não deveriam se comparar aos mais fracos. Todavia, o francês reconhece que há vários tipos de riso, e nem todos passam necessariamente pela constatação de nossa superioridade, sua análise, inclusive, se aproxima da realizada por Freud a respeito das pulsões (HAUGEN, 1988).

A maioria dos textos que retomam a teoria de Hobbes costuma destacar o ponto em que ele discorre sobre o "rir da inferioridade alheia", o autor, no entanto, se dedica igualmente ao riso diante da percepção de nossas próprias capacidades, o que não é, necessariamente, um riso negativo. Em minha pesquisa sobre o trash, isso se aplicaria a uma constatação da possibilidade que temos de rir perante algo que deveria nos provocar medo. Ao rir da morte, de certa forma, estamos lidando com uma série de tabus que a morte representa em nossa sociedade. Essa linha de raciocínio se aproxima da concepção de Freud. Em sua "teoria do alívio", ele argumenta que o riso abre possibilidades para expressarmos impulsos socialmente proibidos, ou reprimidos, relacionados ao sexo e à violência e também para o aspecto lúdico que grande parte das pessoas negligencia na vida adulta. Outros autores também associam a importância do riso a uma forma mais leve de se lidar com a morte. Para Umberto Eco, por exemplo, o riso ajuda a tornar aceitável a ideia insuportável da morte (ALBERTI, 1999; DUARTE, 2006).

A mistura entre medo e humor é muito forte na produção de trash. Muitos filmes que tratam de temas teoricamente amedrontadores como monstros, carnificinas, assassinatos acabam descambando para o humor galhofa. Tal efeito, todavia, não é encontrado de forma igual em todos os indivíduos, e é essa discrepância de reações uma das motivações que levou a psicanálise a se interessar pelo riso. 
Eu pensava que, contrariamente à espirituosidade e ao humor, que não são dados a todo mundo, o cômico seria universal e acessível a todos, não importando o nível cultural. Ora, encontrei adultos dotados do mais alto senso de humor, capazes de tiradas de grande ironia, e que entretanto, em vez de rir, assustavam-se com o cômico. Revendo espetáculos de clowns e filmes cômicos e colocando-me do ponto de vista daqueles adultos, fui obrigado a reconhecer que tinham razão: o que nos faz rir nos filmes cômicos é a representação das situações mais angustiantes possíveis (...). Por que rimos daquilo que nos dá medo? (DIATKINE, 2005).

Gilbert Diatkine (2005), em uma conferência proferida na Sociedade Psicanalítica de Paris, discutiu trabalhos sobre o riso realizados nessa área. Ele afirma que ao mostrar uma cena trágica, o cinema pode suscitar tanto o riso quanto a emoção. No caso do riso, ele acontece porque durante a fruição foram acionados mecanismos que levam o superego a se enganar, pois ele se põe em alerta à toa, o que Freud chama de economia de investimento ${ }^{4}$, gerada pela constatação brusca de que as forças internas mobilizadas para se lidar com um perigo iminente são inócuas, porque o perigo de fato não existe.

Diatkine acredita que, da mesma forma que grande parte dos escritos de Freud sobre o humor se baseia em análises sobre o poder da palavra de duplo sentido, há, no cinema, e nas demais formas de representação, não necessariamente verbais, a possibilidade de se trabalhar com mais de um nível de significação. A ambiguidade entre o trágico e o humorístico estaria, assim, sempre no limite interpretativo do espectador. "Como podemos rir das infelicidades de um vagabundo ameaçado de cair no vazio ou de ser devorado por canibais?”, pergunta-nos o autor. A resposta aparece alinhada à ideia de Freud sobre a constatação do "falso medo": "no cômico, o espectador 'participa psiquicamente' da cena e se identifica primeiro com a vítima, antes de se desligar dela bruscamente, visto ter certeza de que nada de grave acontecerá" (DIATKINE, 2005: 8).

É como se, ao assistirmos uma cena de assassinato, a partir de um determinado instante, conseguíssemos nos afastar suficientemente da cena para aceitar que nada verdadeiramente grave vai acontecer àquele sujeito (ator) e muito menos a nós mesmos. Os filmes trash permitem mais facilmente esse tipo de sensação porque a forma como são conduzidos torna mais fácil esse deslocamento, esse afastamento abrupto em relação à trama. É mais difícil nos identificarmos com os personagens de filmes trash a ponto de sofrermos

\footnotetext{
${ }^{4}$ Ao tratar do riso, Freud separa sua análise em três questões: o chiste, o humor e o cômico. No entanto, diversos autores que se dedicaram ao estudo das considerações de Freud e das relações entre o riso e a psicanálise relativizam tal separação.
} 
juntos com eles. A própria forma de decodificação está, a todo o momento, nos lembrando que aquilo não é para ser levado a sério.

\section{As sutilezas do riso na cultura trash}

Demoníacas formas que assustam e aterrorizam podem prestar-se igualmente a divertir os homens. A monstruosidade tanto pode ser terrível como risível (CARVALHO, 2004: 11).

Um tema interessante na relação entre o riso e o "lixo cultural" é que há, no trash, a questão do efeito involuntário, ou seja, do inacabado, do mal feito, que nesta comunidade significaria aquilo que deu errado, que não atingiu o "correto", o "normal", o esteticamente desejável: um filme, por exemplo, que não foi feito com a intenção de ser trash, mas que acaba sendo celebrado por apresentar falhas na direção, na atuação, nos cenários ou nos efeitos especiais

Os fãs de trash mantêm uma relação bastante ambígua com o cinema canônico. Apesar de apreciarem produções que negam peremptoriamente as regras do que é considerado, pelos árbitros do gosto, cinema "de qualidade", a maior parte deles consome filmes de arte. É interessante como se inverte a lógica proposta por Victor Hugo (2004) quando defende que o grotesco funciona como uma parada obrigatória para a fruição do belo. No caso dos fãs de trash, a obtenção de capital simbólico através do conhecimento e da apreciação dos cânones cinematográficos permite a obtenção de prazer no consumo do que é "lixo". Aqui seria preciso conhecer o belo para desfrutar do grotesco. O belo, nesse caso específico, está relacionado à adequação aos padrões canônicos, ao que se denomina "grande arte" dentro do mundo do cinema. Ao dominar o que é "bom" e o que é "ruim" na sétima arte, o fã se sente à vontade para transitar por essas esferas, adotando distintos posicionamentos em relação a cada grupo de filmes.

[O ridículo] é o oposto do belo (...) e essa causa do riso é peculiar à nossa espécie, porque nenhum animal sobre a terra, exceto o homem, tem algum senso do belo, nem conseqüientemente do deformado. E quanto mais elevado for o nosso senso do belo, mais viva e correta, ao mesmo tempo, será nossa percepção do ridículo; ao passo que aqueles que não têm um gosto correto do belo serão inclinados a rir daquilo que não sabem o que é (MONBODDO apud ALBERTI, 1999: 123). 
É interessante como James Burnett (Lorde Monboddo), filósofo do século XVIII, fala em "percepção correta do ridículo", pois essa ideia apareceu de forma recorrente durante minhas entrevistas e na análise da sociabilidade mantida pelos fãs através da Internet. Ou seja, a noção de que seria possível apontar uma maneira correta de se apreciar o "lixo cultural".

Existe uma diferença muito grande entre o ridículo que aparece no filme do Fellini e o que aparece em um filme do Pepa [responsável pela produtora independente de trash Pepa Filmes] ou mesmo dos Trapalhões, sei lá. (...) Mas é claro que pra quem não entende nada de cinema, Fellini e Renato Aragão podem fazer parte da mesma escola [risos] (...) Quando alguém te indica um filme "porque fulano achou bom", você sempre quer saber quem é o fulano, né, pra saber se pode confiar. A mesma coisa aqui: se alguém te fala "pô, fulano falou que o filme tal é um trash dos bons", você tem que saber quem é o fulano. Porque o que é trash pra mim não é pra você, e não é pro fulano, sabe? (Henrique, 24 anos, estudante de cinema, Rio de Janeiro).

Tem uns caras que confundem trash com "bobajada". Querem rir mesmo do que não tem graça. Ah... o cara tem um narigão, a mulher tem uma perna mecânica, tem um anão vestido de duende. E daí? Tem que separar o que é trash e o que é besteira. Quando o Tarantino coloca uma mulher de perna de metralhadora [situação do filme Planeta Terror (2007), parte do Grindhouse dirigida, na verdade, por Robert Rodriguez]é trash sim, mas nem sempre é, tem que ter um feeling. Senão daqui a pouco Zorra Total é trash também (Javier, 27 anos, engenheiro, Rio de Janeiro).

Aqui é possível fazer, então, duas colocações sobre a importância da posse de capital cultural e subcultural nesse tipo de consumo. Considero que a posse de conhecimento sobre o belo, aqui traduzido em intimidade com os elementos que caracterizam o cinema de arte e suas linguagens, permite ao individuo identificar o ridículo e se deleitar com ele, se assim o desejar. Igualmente, o acúmulo de capital subcultural permite reconhecer, mesmo no conjunto de objetos ridículos, ou, dentro do enorme campo do audiovisual trash, aquilo que merece ser objeto de culto, pois nem todas as besteiras postadas diariamente no YouTube ou veiculadas pela mídia massiva passam por esse processo de redenção cultural.

O contraste entre os entusiastas que circulam com maior desenvoltura pelas ambíguas sensações provocadas por esse tipo de filme fica ainda mais evidente quando ocorre a fruição compartilhada, em cinemas ou eventos dedicados ao gênero, como está explícito no depoimento de André, 17 anos, carioca, estudante do ensino médio:

Eu não gosto quando tem exibição pública, ou muito barata, porque aí vai qualquer um, ficam rindo fora de hora, é gente que não entende nada do assunto... 
“Qualquer um”, no sentido pretendido por esse fã, é qualquer um que não possua o capital subcultural suficiente para lidar com esse tipo de filmes, ou seja, é preciso ser iniciado em trash para poder apreciar o evento de maneira certa. Quem não conhece os códigos internos dessa comunidade de fãs, corre o risco de "rir na hora errada".

\section{Controvérsias sobre o riso no cinema de terror}

O que seremos de nós, criaturas pecadoras, sem o medo, talvez o mais benéfico e afetuoso dos dons divinos? (Jorge de Burgos em $O$ nome da rosa - ECO, 2003: 455).

Na comunidade "Trash, Gore e Terror em Geral", do Orkut, um membro criou um tópico de discussão intitulado “Quem já riu de um filme de terror?”, que aparece citado no título deste artigo. A observação do debate que foi desenvolvido pelos fãs deixa clara a divergência entre uma minoria que gosta do filme pelo que ele é, pela sensação de medo que ele provoca (ou pretende provocar), e a maioria que aprecia a experiência da decodificação, ou seja, que é atraída pela comicidade criada a partir da tentativa fracassada de amedrontar. Assim, o humor defendido por alguns como o fator principal para o apreço pelo gênero gera irritação em outros.

No início do tópico, vinte pessoas responderam citando exemplos de produções que acharam engraçadas e explicando o porquê. O vigésimo-primeiro comentário, porém, interrompe o inventário de momentos cômicos vividos em exibições de filmes de terror. Um fã, identificado como Guilherme, 22 anos, estudante de Comunicação do Distrito Federal, e que foi entrevistado por mim, dá seu depoimento:

Acho bem idiota rir em filme de terror. Rir do fred até que vai pois ele é sarcastico e ironico, mas rir no sexta feira 13 ? puff, odeio playboys que vão ao cinema ver filme de terror e estragam minha diversão, quer rir vai ver american pie, ir ao cinema pra ver filme de terror e rir pra se auto afirmar pra namorada é ridiculo. O que sexta feira 13 tem de engraçado? a cara do jason? QUando fui ao cinema ver exorcita, e todo mundo mijando de rir. Da um tempo, aprendam a assistir um filme de terror, pelo menos não atrapalhe quem está querendo entrar no clima do filme. Rir do que o Fred fala é normal, rir do filme é estupido. sinto muito." ${ }^{, 5}$ (sic)

\footnotetext{
${ }^{5}$ Fred,é o personagem Freddy Krugger, do filme A hora do pesadelo. "Exorcita" trata-se de uma menção ao filme "O exorcista".
} 
É interessante o uso da expressão "aprendam a assistir um filme de terror", pois ela corrobora a hipótese de que existe uma forma correta de se assistir esse tipo de produção. Após a divulgação do comentário acima, outros fãs, que aqui indicarei através de números, se manifestaram sobre o assunto ${ }^{6}$ :

Eu fiquei com raiva das pessoas que riram em Visões, no cinema. Tirou toda minha consentração do filme. (sic) (Fã 1)

Eu tambem acho que quem fica rindo sem motivo de filmes de terror é abobado e só quer se auto-afirmar (sic). (Fã 2)

Engraçado????????????? Quase morri de rir assistindo Premonição 3: hauhauhauhauahuah Quase tive um ataque histérico assistindo A caverna Maldita KKKKKKKKKK. (sic) (Fã 3)

Guilherme, então, escreve mais um comentário:

Alguém que tem cabeça e que consegue ver um filme levando a serio não iria rir de sexta-feira 13, o filme pode até ser trash.. mas não é ao ponto de alguém dar gargalhadas do filme. Eu acho idiota mesmo esse tipo de colocação bem como o topico. Filme de terror só foi feito pra rir quando tem ironia e sarcasmo. pessoas que vão ao cinema ver um filme de terror pra rir, devia ficar em casa ou devia ir a merda. Coisa mais estupida.. Mania de querer ridicularizar tudo. queria ser pateta igual a quem ri desse tipo de filme, talvez eu iria ter uma vida regada a ignorancia e seria mais feliz". (sic)

O comentário nada simpático provoca mais reações dentro do tópico:

Guilherme, saiba que não é nada legal você ficar julgando a inteligência dos outros, principalmente a minha. Tenha mais cuidado com o que escreve depois, blz? Opiniões são opiniões e devem ser respeitadas, independente de concordarmos ou não com elas. Eu ri de Sexta-Feira 13, e daí? Já ri (e continuarei rindo) de muitos filmes que se levavam muito a sério e a série Sexta-Feira 13 continuações tem vários momentos de humor involuntário.Tirando Jason X, vai me dizer que você NÃO riu do Sexta-Feira 13: Parte VI?? (sic). (Fã 4)

Apesar da tentativa de dissuasão por parte de alguns membros da comunidade, Guilherme mantém seu discurso a respeito do comportamento dos demais fãs:

Não, não ri. e to nem ai pro que você diz. Julgo mesmo, pois esse tipo de pessoa estraga a diversão de outras e isso é idiota.Qual a graça em qualquer sexta feira 13? a cara do jason deformada? a mascara do jason cheia de

\footnotetext{
${ }^{6}$ Optei por copiar integralmente os depoimentos, da maneira como foram escritos, para que não houvesse uma mudança no sentido, mesmo que não-intencional. Acredito que pela leitura do embate da forma com que ele foi desenvolvido ajuda a entender mais facilmente o ocorrido do que uma possível tentativa minha de transcrever a situação.
} 
bolinhas? Não, não tem graça. Pessoas morrendo da forma que morrem nos filmes não tem graça. Não foi um filme feito pra ser engraçado e não é. Mas foi o que eu falei, um dia vou tentar virar um bobo alegre, quem sabe assim a vida fica melhor (sic).

Em dois comentários de Guilherme aparece a mesma ideia que liga a atitude de rir dos filmes à ignorância, e, por conseguinte, a ignorância à felicidade: "queria ser pateta igual a quem ri desse tipo de filme, talvez eu iria ter uma vida regada a ignorancia e seria mais feliz" (sic) e "vou tentar virar um bobo alegre, quem sabe assim a vida fica melhor". Aqui, a lógica da superioridade pelo riso aparece invertida: para o jovem, ele é superior aos outros justamente porque não acha engraçado ver "pessoas morrendo da forma que morrem" e os que riem ("patetas", ‘bobos alegres”, “idiotas”, “estúpidos”) o fazem porque não conseguem captar a essência da produção. Outro comentário de Guilherme, depois da argumentação de fãs que consideram filmes da linha de Sexta-Feira 13 cômicos, continuou gerando polêmica:

mermão, eu acompanho esse forum mesmo não postando. Se você gosta de dar risadas ou ir ao cinema e ver nego dando risada em um filme que você está levando a serio, problema é seu (sic)

Quando Incubus (1965) foi exibido no cinesesc, durante aquelas sessões com 2 filmes, que começavam 9:30 e acabavam perto das 02:00, muitas pessoas que frequentavam o lugar não eram fãs de cinema e muito menos de terror. Isso pq as sessões eram de graça. Fui em alguns dias, depois não tive mais vontade (sic). (Fã 5)

Guilherme, tu tem certeza que tu não tá sendo chato? Cara, se tu não gosta de rir de algum filme, seja de terror ou não, problema teu. Só tu não tem o direito de ficar apontando na cara dos outros que é errado. Me sinto ridiculo tendo que dizer esse tipo de coisa obvia pra alguem, mas enfim... (sic). (Fã 4)

A última participação de Guilherme na discussão, antes do tópico ser apagado pelo moderador da comunidade (o que ocorreu devido à discórdia gerada entre os membros):

Rir no cinema é algo que nego faz pra se auto afirmar (eu sou f****, eu não tenho medo e acho esse cara com o machado na cabeça engraçado.) ???? Mas não vou mais falar nada, pois sou piá e não sei nada de filme de terror. Quem ri é que sabe. Os filmes foram feitos pra isso mesmo". (sic)

Ao falar em "rir para se auto-afirmar pra namorada", Guilherme reafirma tanto a noção de superioridade que o riso pode representar quanto a questão da masculinidade 
associada a esse consumo ${ }^{7}$. Nesse caso, rir de um filme de terror visa à negação do medo, nas palavras do próprio jovem: "eu sou $\mathrm{f}^{* * * *}$, eu não tenho medo e acho esse cara com o machado na cabeça engraçado". A ideia de auto-afirmação também é recorrente não só em seus comentários como nos de outros membros que concordam com sua opinião.

Durante as entrevistas que realizei, o tema ("rir ou não rir de um filme de terror") apareceu repetidas vezes e as opiniões variavam muito. De uma maneira geral, existem dois grupos dentro da comunidade de fãs: um defende que filmes trash devem ser respeitados como qualquer outro tipo de filme, ser ruim, ou tosco, como eles gostam de dizer, seria apenas um traço distintivo, assim como o tom "açucarado" seria uma característica das comédias românticas.

O outro grupo, ampla maioria, acredita que rir de um filme trash não só é aceitável como constitui um fim para esse tipo de apreciação, como fica evidente nos seguintes depoimentos:

Eu não consigo enxergar outro jeito de ver esses filmes se não for pra rir. Eu não entendo esses caras [que levam a sério]. Quando o Jason ou o Freddy matam alguém eles fazem o quê? Choram de pena? Aplaudem a belíssima cena que acabaram de ver, com atuações dignas de Oscar? Não, né? Imagino que não, se for tem que internar eles! É lógico que é engraçado, ainda mais se você estiver vendo com uma galera, aí você ri do filme e da risada dos outros, nego já dá gargalhada só pros outros rirem mesmo (Bruno, 17 anos, estudante, Niterói).

Se eu vou ver um filme podreira é pra rir! Se eu quisesse ver um filme para elevar meus conhecimentos sobre a sétima arte, para me emocionar, para refletir, eu veria um iraniano, um Fellini... Se for pra ver um filme ruim, é pra me divertir, e é claro que o riso está implícito nisso... Eu acho que quem leva filme trash a sério na verdade não entendeu a "alma do negócio"... (Marcelo, carioca de 24 anos, estudante de cinema)

A "alma do negócio", que aparece de diferentes formas na argumentação de todos os fãs com quem entrei em contato, é a sensibilidade distinta através da qual um filme ruim pode ser visto. Assim, a "alma do negócio" é não levar a sério a fruição de um produto trash, é rir da própria decodificação, do inusitado de estar assistindo a um filme onde o ator principal é gago, ou em que uma geladeira é serial killer. Os fãs que não enxergam o lado cômico destes filmes são vistos com bastante ressalva pelos aficionados que admitem a prerrogativa de que tais produções são boas justamente por serem muito ruins.

\footnotetext{
${ }^{7}$ Sobre as relações de gênero na subcultura trash, ver CASTELLANO, 2011a. 
Em alguns casos, parece não haver discordância sobre a forma de decodificação. O filme Inseticida (2005) aparece na sessão "terror" do site de vendas DVD World. A sinopse de divulgação, no entanto, é bastante clara em relação aos objetivos da produção:

Prepare-se para a diversão. Inseticida é um filme com muita gosma e litros de sangue falso. Os atores são meio amadores, a maquiagem dá na cara e os insetos - que ficaram gigantes depois de uma experiência - foram desenvolvidos por computadores. São os ingredientes de um filme trash hilariante. Daqueles que nos fazem rir do começo ao fim. Se você sentir medo, procure um médico.

Na comunidade "Trash, Gore e Terror em Geral”, uma pessoa criou um tópico para discutir esse filme, mas houve apenas um comentário - parece que a produção não foi exatamente um sucesso entre os membros - corroborando o tom humorístico:

ridículo, porém divertido, filme classe $\mathrm{Z}$, com insetos gigantes feitos de CGI fundo-de-quintal, e gostosas tomando banho (...) o filme é um lixo total e proposital, com diálogos ridículos, muitas minas gostosas peladas, CGI vergonhoso, atuações patéticas, lógica zero, etc. vejam como eu vi: com uma galera, tomando cerveja. é diversão na certa. Perfect party movie $=$ D. ${ }^{8}$

Se levarmos em consideração as ideias de Hobbes, para quem "a alegria está na comparação de si mesmo com os outros" (SKINNER, 2002: 63), podemos pensar que em filmes de terror, em produções toscas, em paródias etc. os sujeitos que estão em cena são ridicularizados ou sofrem (sejam os atores envolvidos em produções das quais no futuro se envergonharão, sejam as próprias vítimas de um serial killer). $\mathrm{O}$ riso se explicaria porque os sujeitos que estão ali representados (ou representando) sofrem, morrem, são ridículos, "e eu estou confortavelmente sentado em meu sofá, assistindo". Essa ideia apareceu em alguns momentos das minhas entrevistas, como no caso da fala do carioca Rodrigo, 28 anos, formado em jornalismo:

Uma das coisas mais engraçadas do Cinderela Baiana é ver o Lázaro Ramos! O cara deve ter se arrependido muito de ter feito aquilo! Imagina, o cara hoje é todo conceituado e tal, é respeitado, mas tu vai lá no YouTube e tem ele lutando com o Alexandre Pires, numa cena que deve ter sido a pior cena de luta da história do cinema [risos]. Pô, é hilário, eu só fico

\footnotetext{
${ }^{8}$ A única informação disponível no perfil desse usuário do Orkut é que ele é do sexo masculino, dado totalmente dispensável.
} 
imaginando alguém indo perguntar pra ele se é ele mesmo... Eu queria ver o que ele fala nessas horas...

Para Manuela, de 17 anos, estudante de Brasília (e uma das poucas mulheres que aceitaram dar entrevista), a graça da maior parte dos filmes de terror passa pelo reconhecimento da "burrice" das vítimas:

Meu Deus, não tem como dar certo, né? Adolescentes pegam o carro do pai escondido, entram por uma estrada escura, deserta, ou então resolvem explorar uma casa abandonada no meio do nada... É óbvio que vai dar merda. A gente já fica esperando a hora que vai aparecer alguém e matar eles, é bem-feito, né? Não dá pra ter pena de gente assim... É que nem aquele padre dos balões, meu, o cara é tão burro que eu até ri com essa história. Tá, é triste e tal, mas é engraçado também. Imagina se eu pego umas bolas de aniversário e resolvo sair voando pela janela...? A graça tá em você ver que alguém pode ser tão estúpido! ${ }^{10}$

Já em relação à lógica da distinção de Hobbes, o trash comportaria um riso expresso pela ideia de que "eu rio porque me sinto feliz ao constatar minha superioridade em relação ao publico normal, por conseguir extrair prazer de um tipo de produto que em outros causa repulsa, ou, mesmo dentro do grupo, eu rio para mostrar aos meus companheiros que estou realizando a decodificação da maneira correta".

Até a ascensão da chamada pós-modernidade, a forma de distinção mais valorizada passava necessariamente pela fruição e conhecimento das formas elevadas de cultura, ou, de acordo com os conceitos desenvolvidos por Bourdieu (2007), pela acumulação de capital cultural. O gosto aparece aqui como palavra-chave que ajuda a entender de que forma podem ser criadas hierarquias culturais e mesmo econômicas dentro da sociedade. Em A distinção: crítica social do juízo ([1979] 2007) o autor, com base em dados levantados por pesquisas empíricas sobre padrões de consumo na França, nas décadas de 1960 e 1970, desenvolve uma

\footnotetext{
${ }^{9}$ Lázaro Ramos participou do filme Cinderela Baiana, espécie de cinebiografia de Carla Perez. A cena de luta está disponível em: http://www.youtube.com/watch?v=2IyzA2wDCnw

${ }^{10} \mathrm{O}$ tipo de trama descrito por Manuela é característico dos filmes slasher, que costuma abordar a temática de “jovens em apuros". O caso do "padre dos balões” citado pela jovem diz respeito ao ocorrido no Paraná com o padre Adelir Antônio de Carli, que morreu ao tentar bater um recorde voando com balões de festa cheios de gás hélio. O caso ficou famoso e foi alvo de inúmeras piadas e montagens na Internet, que dão conta de paradeiros imaginários para o padre, que desapareceu no mar. No YouTube, são vários os vídeos que "brincam"com o incidente, a maioria é composta por clipes que mostram o padre voando em diversos lugares do mundo (até mesmo na ilha do seriado Lost http://www.youtube.com/watch?v=8MOcZp6ir5E) e ao som de músicas como Vento ventania, do Biquíni Cavadão (http://www.youtube.com/watch?v=_vWoF_Z9g1A) e Superfantástico, do Balão Mágico http://www.youtube.com/watch?v=RhOG_zZFw1Y http://www.youtube.com/watch?v=5NUzG1pIkp4.
} 
complexa tese que salienta a centralidade do consumo nas práticas sociais. Bourdieu relativiza a importância das propriedades materiais e situa a posse de capital simbólico (cultural) como principal fator de distinção dentro da sociedade. Desta forma, o consumo passa a desempenhar um papel central na criação e manutenção de relações sociais de dominação e submissão. A cultura, para o autor, pode ser entendida como uma economia onde os indivíduos investem e acumulam capital. Da mesma forma que no mercado econômico, no cultural alguns gostos são mais valorizados que outros, e determinadas atitudes ajudam certos grupos a obter prestígio no convívio social ${ }^{11}$.

\section{Considerações}

Uma das principais contribuições dos autores do Renascimento dentro deste assunto foi a ênfase no imprevisto e na surpresa como fatores para o riso, principalmente quando há uma quebra na expectativa gerada. Castiglione (apud ALBERTI, 1999), por exemplo, amplia uma ideia de Aristóteles ao defender que o comportamento extravagante, os que vão "um pouco além" são mais propensos ao ridículo, e, assim, a suscitarem o riso: "as vaidades e inconveniências ordinárias provocam repulsão, mas, quando elas assumem uma dimensão exagerada, freqüentemente conduzem ao riso", ou seja, "reduzem a si mesmas ao absurdo, e isto explica por que provocam mais o riso do que a repulsão". Essa ideia pode explicar, em parte, o humor do trash: uma morte "normal" não é engraçada, mas quando as cenas tendem ao absurdo, seja na forma exagerada de representação, ou na escatologia do uso de vísceras, sangue, o desatino explícito a torna trash, e, por isso, sujeita à comicidade. Da mesma forma, um filme ruim não desperta muito interesse, mas um péssimo pode despertar (SKINNER, 2002: 35).

A ideia de que o riso tem estreita ligação com os objetos ridículos, com a surpresa das coisas fora do lugar e com o inesperado também nos ajuda na compreensão do lado engraçado desse tipo de produto cultural. O sucesso dos chamados vídeos incríveis se deve ao encanto que as quebras de expectativa exercem e não somente ao prazer de ver alguém se "dando mal", o que por si só nos levaria ao êxtase, segundo uma análise mais hobbesiana do que a

\footnotetext{
${ }^{11}$ Para uma discussão mais ampla sobre a cultura trash a partir do conceito de distinção de Bourdieu, ver CASTELLANO, 2011b.
} 
que o próprio Hobbes propôs. Tal exame, no entanto, me parece um tanto superficial para dar conta de todo esse fenômeno, pois não é muito difícil nos sentirmos superiores a indivíduos sendo perseguidos por ursos em fúria, tendo a casa destruída por um terremoto ou sofrendo um espetacular acidente de moto.

O interesse por esses vídeos pode passar por uma explicação menos rebuscada do ponto de vista teórico, mas não menos eficiente: o fascínio pelo extraordinário, pelo que foge à ordem. Há, no YouTube, um trecho de reportagem sobre a Festa da Uva, exibida em 1999 no programa Jornal do Almoço da emissora RBS TV, afiliada da Rede Globo no Rio Grande do Sul, em que o repórter Lasier Martins apresenta diferentes tipos de uva e, ao mexer em um dos cachos, toca em um fio de eletricidade e toma um violento choque, o que acabou indo ao ar, pois se tratava de uma tomada ao vivo. O vídeo foi parar no site em novembro de 2006 (destino de praticamente todas as imagens inusitadas veiculadas atualmente) e teve um grande número de acessos logo no primeiro dia ${ }^{12}$.

O sucesso desse vídeo, incluído na categoria trash a partir da definição de paracinema comentada no início deste artigo, pode ser analisado pela ruptura na sequência harmônica dos fatos na matéria que ia ao ar. Como nos explica Alberti (1999: 41), rimos quando "uma pessoa grave, capaz ou digna sofre algum acidente ligado à baixeza, como a queda cômica, em que as idéias de dignidade e gravidade contrastam com as 'contorções do corpo' e a 'sujeira das roupas' decentes”. Essa perspectiva apresentada pela autora, a respeito da teoria de Hutcheson (um grande crítico de Hobbes), nos auxilia a compreender por que um senhor trajado em terno e gravata tomando um choque ao vivo em um telejornal e se estatelando no chão nos leva ao riso. A causa dessa incitação ao humor seria motivada pela "junção de ideias contrárias". Por isso fazem muito sucesso na Internet vídeos com erros, quedas e gafes de jornalistas e repórteres, pois esses momentos quebram o ar de seriedade que se espera desse tipo de produção televisiva. O erro de um ator não tem tanta graça, pois apesar de ser um deslize, ele ocorre em um ambiente menos sério, onde há, normalmente, espaço para o humor. Tanto que as falhas na gravação de dramaturgia vão ao ar dentro da própria programação das emissoras, como é o caso do quadro Falha Nossa, do Vídeo Show (Rede Globo), já os problemas ocorridos durante a transmissão dos telejornais só podem ser revistos quando vão parar no YouTube por vias extra-oficiais.

\footnotetext{
${ }^{12} \mathrm{http}: / /$ br.youtube.com/watch?v=ETUEWN7pte8 (vídeo original do choque)
} 
Pode-se rir. Há de quê: rir do outro, desse fantoche ridículo, nu, que tem um sexo, que peida e arrota, que defeca, que se fere, que cai, que se engana, que se prejudica, que se torna feio, que envelhece e que morre - um ser humano, bolas!, uma criatura decaída (MINOIS, 2003: 113).

Em parte, essa explicação esbarra na mesma justificativa do lado cômico encontrado no grotesco: o mundo alheado, tornado estranho, descontextualizado. "O repentino e a surpresa são partes essenciais do grotesco", lembra-nos Kayser (2003), e acredito que esse é o caminho para a compreensão do efeito cômico gerado pelo trash e mesmo para o exercício de uma definição mais clara para o termo. O vídeo institucional do Mc Donald's, citado por Sconce (1995) como um exemplo de paracinema, só pode ser assim considerado fora de um treinamento para funcionários, da mesma forma que rir de um assassinato em um filme só pode ser engraçado se a ideia inicial for não se envolver com a trama, se o espectador não levar a sério o que está sendo apresentado, não se identificar com o personagem.

Ao final da discussão de The Elements of Law, Hobbes faz uma sugestão à qual nunca retorna, mas que é muito interessante. Ele fala "que algumas vezes nós rimos não porque sentimos desprezo por alguma pessoa em particular, mas porque nos damos conta de algum absurdo mais geral". Esse riso, embora ainda seja uma expressão do nosso escárnio, nos leva a uma espécie de comunhão, pois "em vez de debochar diretamente de outras pessoas, nos unimos para ridicularizar alguma característica burlesca do mundo e de seus absurdos". Assim, de um ponto de vista mais filosófico ou existencial, acredito que o riso do trash pode ser encarado, acima de tudo, como um grande riso sobre o absurdo do mundo (SKINNER, 2002: 57).

\section{Referências}

ALBERTI, Verena. O riso e o risível na história do pensamento. Rio de Janeiro: Jorge Zahar, 1999.

BOURDIEU, Pierre. A distinção: crítica social do julgamento. São Paulo: Edusp, 2007.

CARVALHO, Luciana Gonçalves de. O diabo e o riso na cultura popular. Enfoques, v.3, n. 1, p. 1-19, 2004.

CASTELLANO, Mayka. Lixo é coisa de homem! As questões de gênero na subcultura cinematográfica do trash. InTexto, v. 2, p. 251-271, 2011 a. 
Distinção pelo "mau gosto" e estética trash: quando adorar o lixo confere status. Comunicação \& Sociedade, v. 32, p. 153-174, 2011 b.

DIATKINE, Gilbert. Sobre o riso. Conferência proferida na Sociedade Psicanalítica de Paris, em novembro de 2005. Disponível em:

http://www.sbpsp.org.br/siteinternosbpsp/trabalhos_cientificos/WS1904.doc.

DUARTE, Lélia Maria Parreira. A criatividade que liberta: riso, humor e morte. In: Ironia

e humor na literatura. São Paulo: Alameda, 2006, p. 51-67.

ECO, Umberto. O nome da rosa. Rio de Janeiro: O Globo, 2003.

História da feiúra. Rio de Janeiro: Record, 2007.

FELINTO, Erick. Videotrash: o YouTube e a Cultura do "Spoof" na Internet. Anais do XVI Encontro da Compós, Curitiba, 2007.

FREIRE FILHO, João. Mídia, consumo cultural e estilo de vida na pós-modernidade. ECO-PÓS, v. 6, $\mathrm{n}^{\circ} 1$, p. $72-97,2003$.

FREUD, Sigmund. Le mot d'esprit et ses rapports avec l'inconscient. Paris: NRF, 1969.

HAUGEN, Arne Kjell. Baudelaire: le rire et le grotesque. Littérature. n. 72, dezembro de 1988.

HUGO, Victor. Do grotesco e do sublime. Prefácio de Cromwell. São Paulo: Perspectiva, 2004.

JANCOVICH, Mark. Cult fictions: cult movies, subcultural capital and the production of cultural distinctions. Cultural Studies, v. 16, n.2, p. 306-322, 2002.

KAYSER, Wolfgang. O grotesco: configuração na pintura e na literatura. São Paulo: Perspectiva, 2003.

MINOIS, George. História do riso e do escárnio. São Paulo: Editora UNESP, 2003.

SCONCE, Jeffrey. "Trashing" the academy: taste, excess, and an emerging politics of cinematic style. Screen, v. 36, p. 371-393, 1995.

SONTAG, Susan. Notas sobre o camp. In: Contra a interpretação. Porto Alegre: L\&PM, 1987, p. 318-337.

THORNTON, Sarah. Club cultures: music, media and subcultural capital. Oxford: Polity, 1995.

Original recebido em: $30 / 10 / 2012$

Aceito para publicação em: 03/12/2012 
Resumo sobre autor

Bacharel em jornalismo pela Universidade Federal do Rio de Janeiro. Mestre e doutoranda pelo PPGCOM da Escola de Comunicação da UFRJ, na linha Mídia e Mediações Socioculturais. 